\title{
Article \\ Calculated Shoulder to Gauge Ratio of Fatigue Specimens in PWR Environment
}

\author{
Igor Simonovski ${ }^{1}$ *, Alec Mclennan ${ }^{2}$, Kevin Mottershead ${ }^{2}$, Peter Gill ${ }^{2}$, Norman Platts ${ }^{2}$, Matthias Bruchhausen ${ }^{1}$, \\ Joshua L. Waters ${ }^{2}$, Marc Vankeerberghen ${ }^{3}$, Germán Barrera Moreno ${ }^{4}$, Sergio Arrieta Gomez ${ }^{5}$ \\ and Radek Novotny ${ }^{1}$
}

1 European Commission, Joint Research Centre, Westerduinweg 3, 1755 ZG Petten, The Netherlands; Matthias.Bruchhausen@ec.europa.eu (M.B.); Radek.Novotny@ec.europa.eu (R.N.)

2 Jacobs, Walton House 404 Faraday Street, Warrington WA3 6GA, UK; Alec.Mclennan@jacobs.com (A.M.); Kevin.Mottershead@jacobs.com (K.M.); Peter.Gill@jacobs.com (P.G.); Norman.Platts2@jacobs.com (N.P.); Joshua.L.Waters@jacobs.com (J.L.W.)

3 Nuclear Materials Science Institute, Studiecentrum voor Kernenergie, Centre d'Étude de l'Énergie Nucléaire (SCK CEN), Boeretang 200, 2400 Mol, Belgium; marc.vankeerberghen@sckcen.be

4 Centro de Investigaciones Energéticas, Medioambientales y Tecnológicas (CIEMAT), Avenida Complutense 40, 28040 Madrid, Spain; german.barrera@ciemat.es

5 Laboratory of Materials Science and Engineering, University of Cantabria (UNICAN), Avda. de los Castros, s/n, 39005 Santander, Spain; sergio.arrieta@unican.es

* Correspondence: Igor.Simonovski@ec.europa.eu; Tel.: +31-(0)224-56-5072

\section{check for} updates

Citation: Simonovski, I.; Mclennan, A.; Mottershead, K.; Gill, P.; Platts, N.; Bruchhausen, M.; Waters, J.L.; Vankeerberghen, M.; Moreno, G.B.; Gomez, S.A.; et al. Calculated Shoulder to Gauge Ratio of Fatigue Specimens in PWR Environment. Metals 2021, 11, 376. https:// doi.org/10.3390/met11030376

Academic Editors: Vincenzo Crupi and Janice Barton

Received: 15 December 2020

Accepted: 18 February 2021

Published: 24 February 2021

Publisher's Note: MDPI stays neutral with regard to jurisdictional claims in published maps and institutional affiliations.

Copyright: (c) 2021 by the authors. Licensee MDPI, Basel, Switzerland. This article is an open access article distributed under the terms and conditions of the Creative Commons Attribution (CC BY) license (https:/ / creativecommons.org/licenses/by/ $4.0 /)$.

\begin{abstract}
A ratio of shoulder to gauge displacements (S2G) is calculated for three different fatigue specimens in a pressurized water environment. This ratio needs to be known beforehand to determine the applied shoulder displacements during the experiment that would result in the desired strain amplitude in the gauge section. Significant impact of both the applied constitutive law and specimen geometry on the S2G is observed. The calculation using the fully elastic constitutive law results in the highest S2G values and compares very well with the analytical values. However, this approach disregards the plastic deformation within the specimens that mostly develops in the gauge section. Using the constitutive laws derived from actual fatigue curves captures the material behaviour under cyclic loading better and results in lower S2G values compared to the ones obtained with the fully elastic constitutive law. Calculating S2G values using elastic-plastic constitutive law based on the monotonic uniaxial tensile test should be avoided as they are significantly lower compared to the ones computed with elastic-plastic laws derived from hysteresis loops at half-life.
\end{abstract}

Keywords: environmental fatigue; 304 stainless steel; air; PWR primary water; $300{ }^{\circ} \mathrm{C}$

\section{Introduction}

In the design of the current fleet of pressurized water reactors (PWR), environmentally assisted fatigue (EAF) is a failure that was not originally taken into account by design codes, e.g., ASME. In the meantime, experimental data have shown the significant negative effect of the PWR environment on the fatigue life of common reactor steels and methods for assessing EAF have been developed [1,2] and incorporated, e.g., into US Nuclear Regulatory Commission Regulatory Guides (NUREG).

However, current guidance provided in NUREG CR-6909 [1] for assessing environmental fatigue predicts high-usage factors that are not reflected in actual plant experience [3]. This suggests that the most recent review of CR-6909 contains significant conservativisms. Proper understanding of EAF and reduction of unnecessary conservativism are important for the long-term operation (LTO) of current nuclear power plants (NPPs). Extension of the life-time of current NPPs is an efficient means to provide low carbon energy and contributes to the climate change fight. Accordingly, different proposals are currently being discussed to further improve guidance for assessing EAF in NPPs [4-8]. 
To characterize environmental effects on fatigue, extensive test campaigns are performed in which the fatigue life under reference conditions (usually air at room temperature) is compared to the fatigue life in the environment. The reference tests are normally performed using solid specimens as described in the relevant ISO or ASTM standards. For the tests in environment, two approaches are commonly used. One option is using hollow specimens in which the water environment is flowing through the specimen. The other option is to use the same solid specimens as used in the reference tests in air, and carry out the test in an autoclave filled with the environment. The discussion how to compare results from both types of specimens is still ongoing [9-12].

Both approaches have their inherent advantages and disadvantages. For hollow specimens, the gauge section is easily accessible, so the strain in the gauge section can be measured directly by means of an extensometer. However, having the pressurized environment inside the specimen leads to additional stress components (like hoop stress), which are not present in the reference tests. Depending on the experimental configuration, temperature gradients through the specimen wall may exist that also induce strains and stresses. The stress distribution in a hollow specimen is therefore quite different from the membrane stress found in solid specimens during reference testing. These differences in stress distribution could potentially have an impact on the sensitivities to the environment. It is also difficult to machine the inner surface of hollow specimens, which limits their usefulness for the study of parameters like surface roughness in EAF, and makes postmortem analysis more time-consuming.

Using solid specimens in an autoclave avoids these problems, since the stress state is the same as for the reference tests in air, the specimen surface can easily be machined, and by applying a sufficient soaking time before starting the test, a constant specimen temperature can be achieved. On the other hand, the presence (and wear) of gaskets at the point where the pull rods pass through the autoclave wall complicates the force measurement. Furthermore, putting the specimen in an autoclave with a PWR environment makes assuring proper strain measurement and/or control a challenge. Such test rigs can use linear variable displacement transducers (LVDTs) that are connected to the specimen shoulder [13]. Ideally, a LVDT would be placed at the gauge section. However, since a crack can initiate at the points of contact between the extensometer and the specimen in PWR water environments, tests are mostly done without such a LVDT. The strain in the gauge section is then obtained from the displacement measured at the shoulder by applying a shoulder to gauge (S2G) conversion ratio. One needs to obtain the S2G ratio prior to the experiment, either by separate sets of tests in an air environment or by finite element simulations.

The current work demonstrates how the S2G ratio is obtained for a number of specimen geometries used in the INCEFA-PLUS project [14] and explores the sensitivity of the conversion factor on the underlying constitutive material law. The authors are not aware of literature dealing with the specific S2G issue.

\section{Shoulder-to-Gauge (S2G) Ratio}

Shoulder-to-gauge ratio, S2G, is defined as the ratio of the change of shoulder, $\Delta L_{\text {shoulder }}$ and gauge length, $\Delta L_{\text {gauge, }}$ as shown in Equation (1). Specimen dimensions are given in Figure 1. For a fully elastic material, the change in the specimen length due to the applied axial load $F$ is given by Equations (2)-(4), where $D 1, D 3, L 1, L 2, L 3$ and $R$ stand for diameter, length and transition region radius dimensions (see Figure 1 ) and $E$ for modulus of elasticity. The smaller cross section in the gauge section leads to higher stresses than in the shoulder. In the presence of plasticity, the plastic strain is therefore higher in the gauge than in the shoulder, and the fully elastic values provide the upper limit of the S2G ratio.

$$
\mathrm{S} 2 \mathrm{G}=\Delta L_{\text {shoulder }} / \Delta L_{\text {gauge }}
$$




$$
\begin{gathered}
S 2 \mathrm{G}_{\text {elastic }}=\frac{\overbrace{\Delta L 1_{\text {elastic }}+\Delta L 2_{\text {elastic }}+\Delta L 3_{\text {elastic }}}^{\Delta L 1_{\text {elastic }}}}{\underbrace{}_{\Delta L_{\text {gauge }}}} \\
\Delta L 2_{\text {elastic }}=\frac{F}{\pi \cdot E}\left[\frac{2 \cdot L 2}{\frac{F 1 \cdot L 1 \cdot 4}{R \cdot\left(L 2^{2}+D 1 \cdot R\right)}+\frac{2}{D \cdot D 1^{2} \cdot E}} \cdot \operatorname{arctantic}\left(\frac{L 2}{R \cdot \sqrt{\frac{D 1}{R}}}\right)\right] \\
\Delta L 3_{\text {elastic }}=\frac{F \cdot L 3 \cdot 4}{\pi \cdot D 3^{2} \cdot E}
\end{gathered}
$$

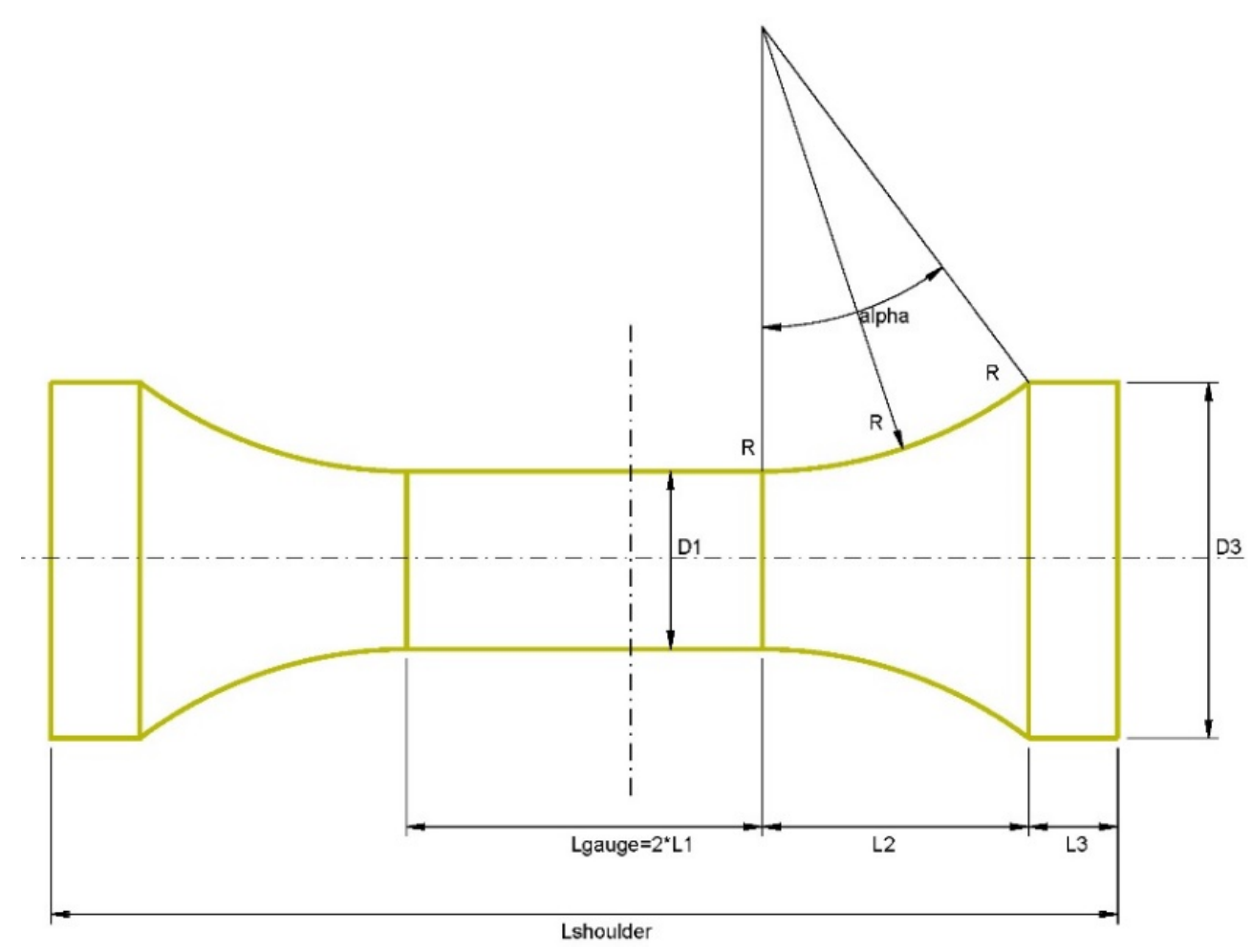

Figure 1. Sketch of a fatigue specimen.

\section{Finite Element Model}

The finite element method is employed to compute the S2G ratios of different specimens subjected to cyclic loading. Two-dimensional axisymmetric finite element models (FEMs) are used with the ABAQUS solver (2017, Dassault Systèmes ${ }^{\circledR}$, Paris, France). Length-wise, only one half of the specimens is modelled due to the symmetry.

\subsection{Specimen Geometries}

Three different round solid specimen geometries, Figure 2, are analysed: (1) JRC, (2) SCK-CEN and (3) CIEMAT. The JRC and CIEMAT specimens exceed the ASTM-E606 [15] recommended (transition region radius)/(gauge diameter) ratio but conform with ISO 12106 [16], Table 1. SCK-CEN and CIEMAT specimens use a smaller gauge diameter than the recommended minimum 6.35 (ASTM) and 5-10 (ISO) $\mathrm{mm}$. This is due to the load restriction on the fatigue testing machines. The recommended gauge length to diameter ratio is observed for all geometries. The specimen are manufactured using a turning process. Two different surface finishes are tested: (a) fine laboratory finish (using a $9 \mu \mathrm{m}$ 5230 microtec slurry coated paper first, 80 passes, followed by $5 \mu \mathrm{m} 5230$ microtec slurry 
coated paper, 140 passes) and (b) worst case typical plant finish where grinding is applied after the turning, obtaining a total height of the roughness profile $R_{t}$ of $50 \pm 10 \mu \mathrm{m}$.

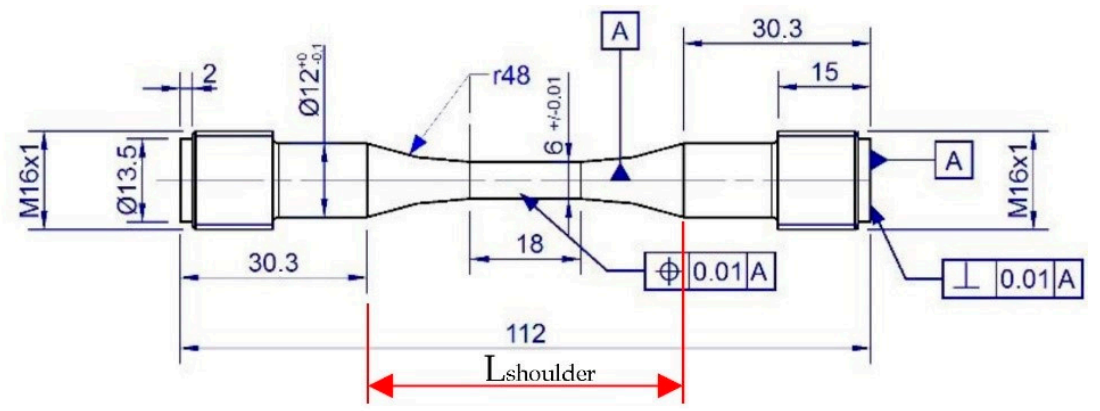

(a)

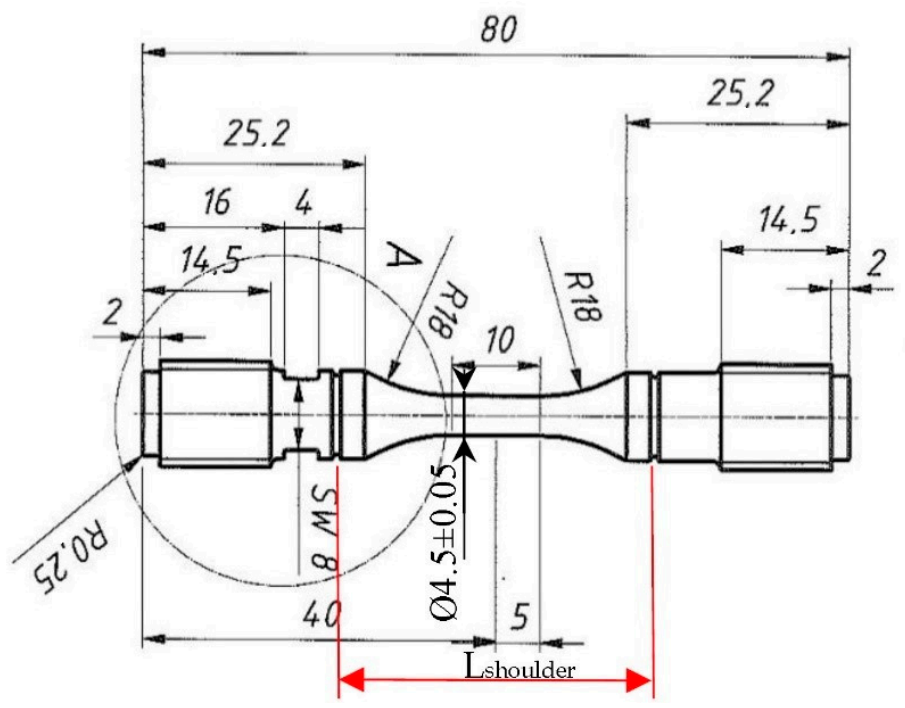

(b)

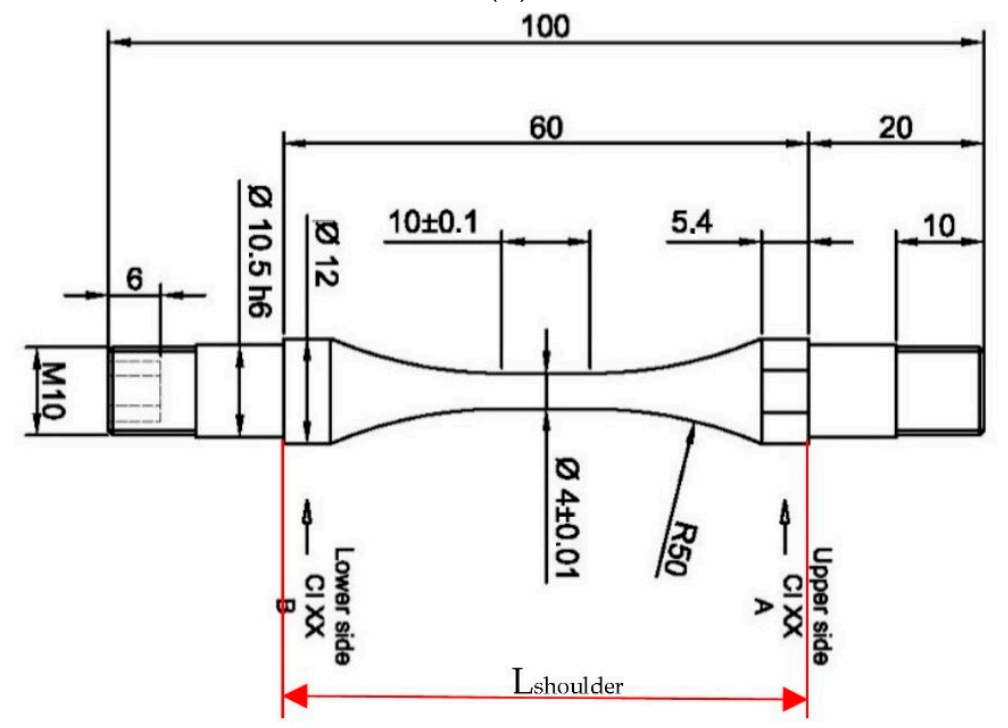

(c)

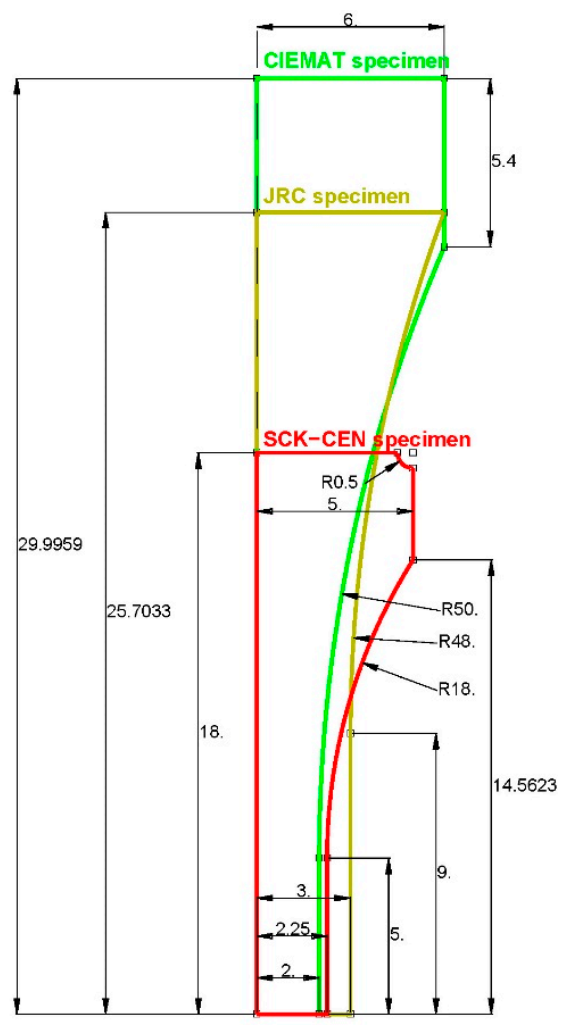

(d)

Figure 2. JRC (a), SCK-CEN (b), CIEMAT (c) specimens and geometries of the 2D axisymmetric FEM models (d). 
Table 1. Comparison of specimens against the ASTM-E606 and ISO 12106 recommended values.

\begin{tabular}{cccc}
\hline Specimen & $\begin{array}{c}\text { (Gauge Length 2* } \mathbf{L 1}) /(\text { Gauge } \\
\text { Diameter D1) }\end{array}$ & $\begin{array}{c}\text { (Transition Region Radius } \\
\text { R)/(Gauge Diameter D1) }\end{array}$ & Gauge Diameter D1 (mm) \\
\hline ASTM-E606 & $3 \pm 1$ & $4 \pm 2$ & 6.35 \\
ISO 12106 & $>2$ & $>2$ & $5-10$ \\
JRC & $18 / 6=3$ & $48 / 6=8$ & 6 \\
SCK-CEN & $10 / 4.5=2.22$ & $18 / 4.5=4$ & 4.5 \\
CIEMAT & $10 / 4=2.5$ & $50 / 4=12.5$ & 4 \\
\hline
\end{tabular}

\subsection{Material}

INCEFA-PLUS uses AISI 304L stainless steel as a common material [17]. Several types of constitutive responses are evaluated, as defined in the coming sections.

\subsubsection{Elastic and Elastic-Plastic}

Monotonic tensile test of AISI $304 \mathrm{~L}$, performed at $300^{\circ} \mathrm{C}$ in air [18] is used for obtaining the modulus of elasticity, $E=185,667 \mathrm{MPa}$, Poisson ratio, $v=0.29$, and true strain versus plastic strain data. The corresponding results are labelled as "Elastic" or "ElasticPlastic". Stress-strain data in tabular form are given in [18].

\subsubsection{Combined Isotropic and Kinematic Hardening}

Fatigue hysteresis loops of AISI $304 \mathrm{~L}$ at half-life, N25/2, performed at $300{ }^{\circ} \mathrm{C}$ in air $[19,20]$, are used for calibrating the isotropic and kinematic hardening components. Modulus of elasticity is taken as $E=163,400.5 \mathrm{MPa}$, while the Poisson ratio is $v=0.30[19,20]$.

One calibration is performed for $\Delta \varepsilon=0.6 \%$ and another for $\Delta \varepsilon=1.2 \%$. The corresponding results are labelled as "IsoKinHard, $\Delta \varepsilon=0.6 \%$ " and "IsoKinHard, $\Delta \varepsilon=1.2 \%$ ". $\Delta \varepsilon$ stands for the total strain range. These strain ranges were selected during the INCEFA-PLUS project experimental campaign, see also section on loads and boundary conditions. The isotropic hardening, i.e., expansion of the yield surface, is given by a table of equivalent stress, defining the size of the elastic range and corresponding equivalent plastic strain (Table 2). For the kinematic part, only the upper part of N25/2 loop is selected, up to the unloading point: from point $\varepsilon_{p}^{0}$ to point $\left(\sigma_{n}, \varepsilon_{n}\right)$ (see Figure 3$)$. The plastic strains are then calculated from an origin shifted to $\varepsilon_{p}^{0}$, Equation (6), following the procedure defined in ABAQUS documentation for calibrating to a stabilized loop.

$$
\varepsilon_{i}^{p l}=\varepsilon_{i}-\frac{\sigma_{i}}{E}-\varepsilon_{p}^{0}
$$

Table 2. Isotropic hardening properties, using the ABAQUS “* Cyclic Hardening" option.

\begin{tabular}{cccc}
\hline \multicolumn{2}{c}{$\Delta \varepsilon=\mathbf{0 . 6 \%}$} & \multicolumn{2}{c}{$\Delta \varepsilon=\mathbf{1 . 2} \%$} \\
\hline Stress (MPa) & Plastic Strain (/) & Stress (MPa) & Plastic Strain (/) \\
\hline 81.2 & 0.0 & 110.0 & 0.0 \\
91.2 & 0.0592 & 120.0 & 0.0592 \\
91.2 & 1.4798 & 120.0 & 1.4798 \\
\hline
\end{tabular}




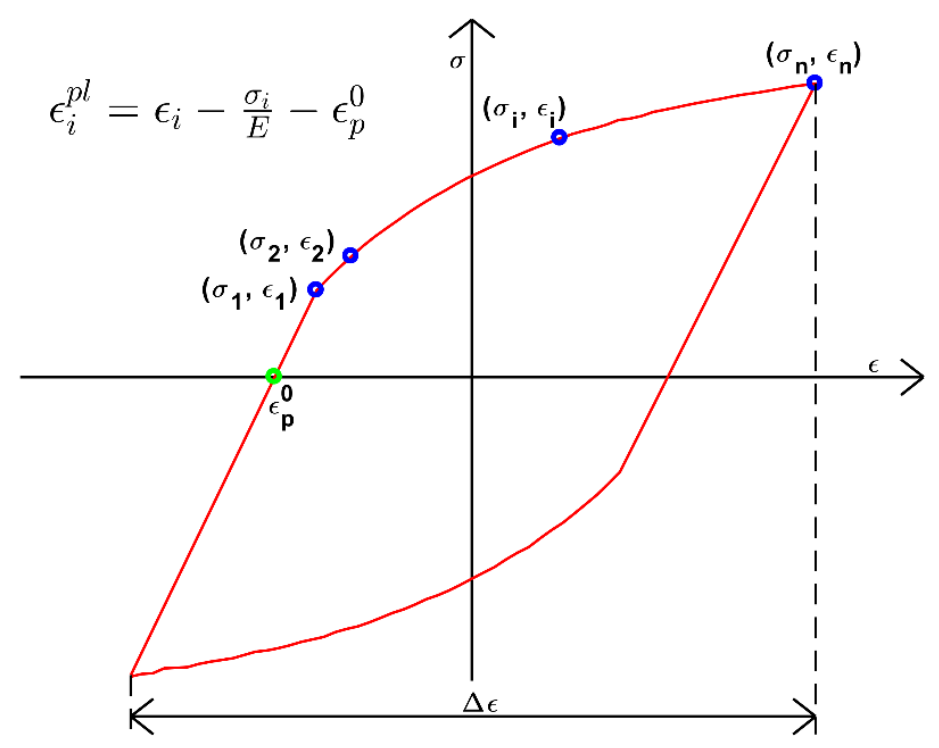

Figure 3. Calibrating the kinematic hardening, $\left(\sigma_{i}, \varepsilon_{i}\right)$ pairs to the $\mathrm{N} 25 / 2$ loop. Point $\left(\sigma_{1}, \varepsilon_{1}\right)$ is the end of the linear elastic region, following the un-loading half of the loop.

\subsubsection{Multilinear Kinematic Hardening}

In this section, N25/2 loops from a collection of cyclically tested 304 stainless steels at $300{ }^{\circ} \mathrm{C}$ in air are used [21]. Modulus of elasticity is taken as $E=174,000 \mathrm{MPa}$, while the Poisson ratio as $v=0.30$. For the kinematic hardening, only the upper parts of N25/2 loops are selected, following the same procedure as just described in the previous section. Once the plastic strains have been calculated using Equation (6), a piecewise Ramberg-Osgood curve, Equation (7), is fitted to the such-obtained stress-strain data. To capture the correct hardening behaviour at a large range of strain amplitudes, different parameters above and below a given strain threshold of amplitude are used: JACOBS used a $0.4 \%$ strain threshold, while in the INCEFA project, a threshold of $0.33 \%$ was selected, Table 3 . The corresponding results are labelled as "JACOBS" and "INCEFA".

$$
\varepsilon_{\text {plastic }}=\left(\frac{\sigma}{K}\right)^{1 / n}
$$

Table 3. Ramberg-Osgood parameters for JACOBS and INCEFA constitutive laws.

\begin{tabular}{cccccccccc}
\hline- & \multicolumn{2}{c}{$\varepsilon \leq \mathbf{0 . 4 \%}$} & \multicolumn{2}{c}{$\varepsilon>\mathbf{0 . 4}$} & - & \multicolumn{2}{c}{$\varepsilon \leq \mathbf{0 . 3 3 \%}$} & \multicolumn{2}{c}{$\varepsilon>\mathbf{0 . 3 3 \%}$} \\
- & $K(\mathrm{MPa})$ & $\boldsymbol{n}(/)$ & $K(\mathbf{M P a})$ & $\boldsymbol{n}(/)$ & - & $\boldsymbol{K}(\mathrm{MPa})$ & $\boldsymbol{n}(/)$ & $\boldsymbol{K}(\mathbf{M P a})$ & $\boldsymbol{n}(/)$ \\
\hline JACOBS & 800 & 0.213 & 2800 & 0.425 & INCEFA & 770 & 0.234 & 2500 & 0.425 \\
\hline
\end{tabular}

Full details of all the calibrations are given in [22]. Data sets used for calibration are given in $[19,20]$. Comparison of the used constitutive models is given in Figure 4. 


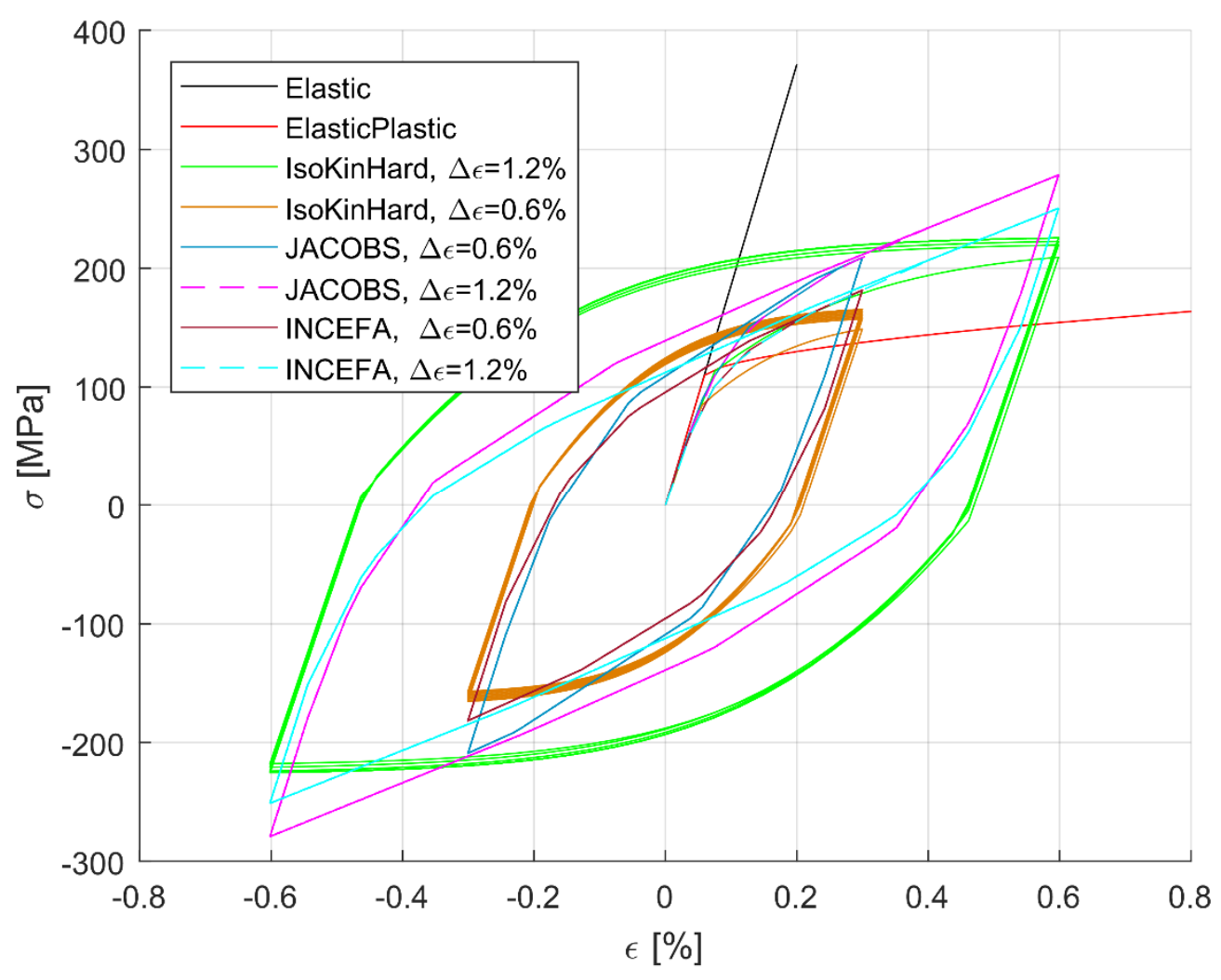

Figure 4. AISI 304L material models, used for FEM models [22].

\subsection{Loads and Boundary Conditions}

During the INCEFA-PLUS experimental campaign, strain ranges of $\Delta \varepsilon=0.6 \%$ and $\Delta \varepsilon=1.2 \%$ in the gauge section were selected to reach well into the low-cycle regime. To make sure these strain ranges in the gauge section are obtained in the FEM model, a userdefined amplitude (UAMP) displacement load in the vertical direction is applied to the top edge of a specimen. The user subroutine monitors the displacement at the gauge length, throughout the simulation. Once the displacement results in the target gauge strain range ( $\Delta \varepsilon=0.6 \%$ or $\Delta \varepsilon=1.2 \%$ ), the displacement load is shortly kept constant and then reversed, Figure 5. This results in a trapezoidal load waveform, keeping the gauge strain rate constant during load-up and load-down for both gauge strain ranges. The displacement load is applied on a reference point (RP) of which vertical and rotational displacements of the RP are kinematically linked to the vertical and rotational displacements of the top edge of the specimen. Vertical displacement of the RP node is therefore equal to the vertical displacements of the nodes on the top edge of the specimen. The same is valid for the rotational degree of freedom of the RP node and nodes on the top edge of the specimen. This simplifies the extraction of the axial force during the post-processing phase. Vertical displacements of the nodes on the bottom edge of the specimen are constrained. Horizontal displacements of nodes on the specimen at the symmetry line do not need to be constrained as this is done automatically due to the application of 2D axisymmetric model. Five load cycles are applied at a frequency of $0.5 \mathrm{~Hz}$. 

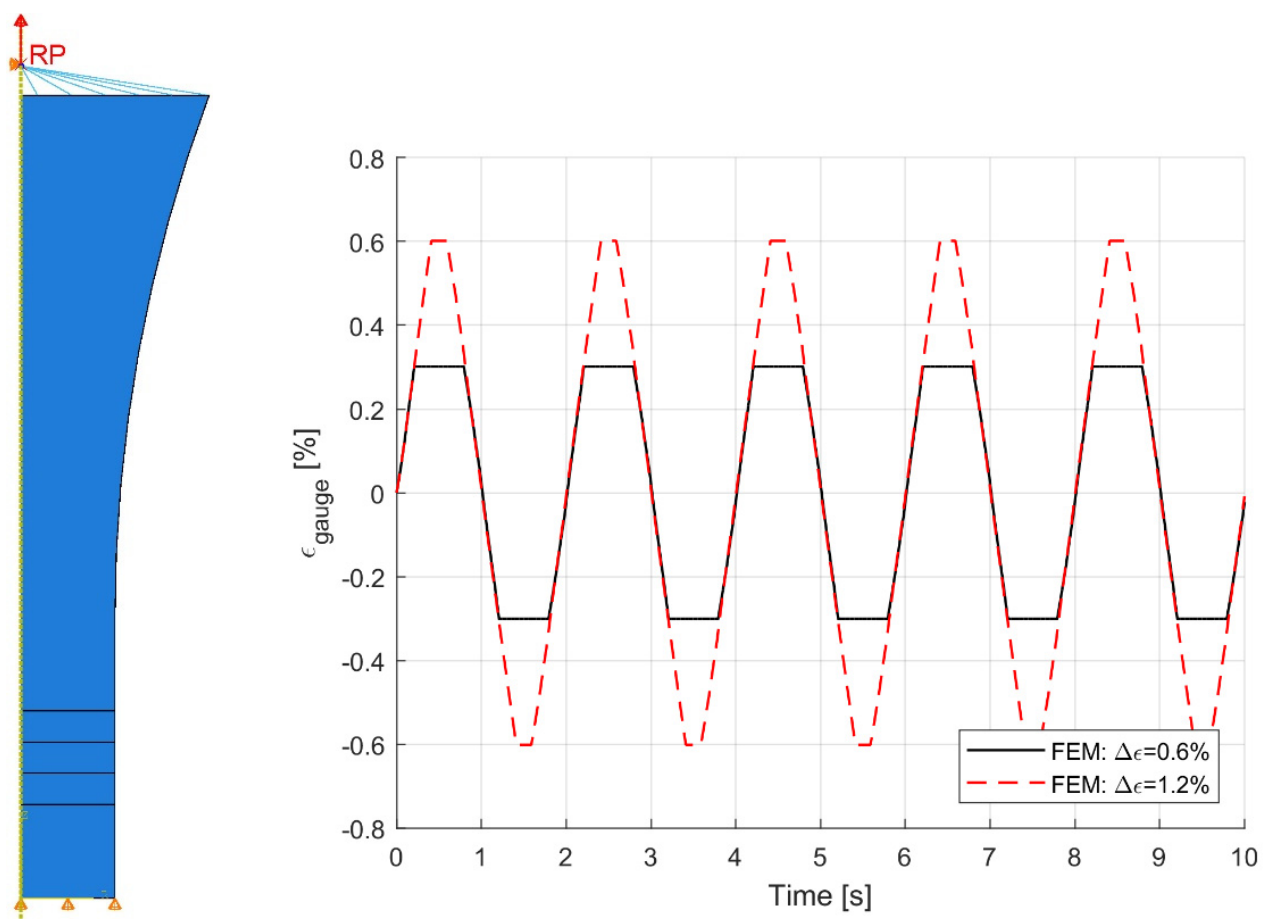

Figure 5. Load and boundary conditions.

\subsection{Mesh}

Second order CAX8R elements are used with the JRC specimen model having 2860 elements, the SCK-CEN model 1425 elements and the CIEMAT model 3020 elements. Table 4 provides the mesh quality check. Since the models are tens of $\mathrm{mm}$ in size and a target element size of $0.2 \mathrm{~mm}$ is used, the resulting mesh is very fine. Higher mesh densities have also been used to make sure the results with the above given meshes are mesh independent but were not used further due to higher computational cost. Validation of the FEM model was performed by comparing the results of two independently developed FEM models (JRC and CIEMAT) with the SCK-CEN experimental results [13]. The results matched very well.

Table 4. Finite element mesh statistics.

\begin{tabular}{cccc}
\hline Specimen & $>\mathbf{1 0}(\mathbf{\%})$ & $\begin{array}{c}\text { Aspect Ratio } \\
\text { Average }\end{array}$ & Worst \\
\hline JRC & 0 & 1.39 & 1.93 \\
SCK-CEN & 0 & 1.33 & 3.73 \\
CIEMAT & 0 & 1.57 & 2.03 \\
\hline
\end{tabular}

\section{Results}

\subsection{S2G Ratios}

Displacements of nodes at the ends of gauge and shoulder sections of the model are extracted from the simulation results as they represent changes of gauge and shoulder lengths, enabling one to calculate the S2G values. S2G values, computed as average S2G values at maximal/minimal load over the five load cycles are given in Table 5. One can see a considerable dependence of S2G values on the chosen constitutive response. Elastic constitutive response results in highest $S 2 \mathrm{G}$ values and is used for a comparison with the linear elastic results Equation (1). FEM results match well with the linear elastic S2G values. Elastic-plastic properties from uniaxial (monotonic) tensile test were used initially [13] and result in the lowest $S 2 \mathrm{G}$ values. These values can be considered representative of the few initial cycles only. For N25/2 cycle, the isotropic kinematic hardening and JACOBS and 
INCEFA constitutive models are representative. JACOBS and INCEFA S2G values differ only slightly and are considered by the authors to be the most representative since they are based on material data from a collection of cyclically tested 304 stainless steels.

The highest S2G values are obtained for CIEMAT specimen. This can be explained by: (a) its largest length and (b) smallest gauge to specimen length ratio (0.17). SCK-CEN specimen are the shortest but still have lower gauge to specimen length ratio compared to the JRC specimen ( 0.28 versus 0.35 ). Consequently, the elastic S2G values of SCK-CEN specimen are slightly higher compared to the JRC ones. Once the plasticity effects are accounted for, the differences in S2G values between the SCK-CEN and JRC specimens are minimal.

Table 5. S2G values.

\begin{tabular}{|c|c|c|c|c|c|c|}
\hline \multirow{2}{*}{ Constitutive Law } & \multicolumn{2}{|c|}{ JRC } & \multicolumn{2}{|c|}{ SCK-CEN } & \multicolumn{2}{|c|}{ CIEMAT } \\
\hline & $\Delta \varepsilon=0.6 \%$ & $\Delta \varepsilon=1.2 \%$ & $\Delta \varepsilon=0.6 \%$ & $\Delta \varepsilon=1.2 \%$ & $\Delta \varepsilon=0.6 \%$ & $\Delta \varepsilon=1.2 \%$ \\
\hline Analytic ${ }_{\text {Elastic }}$ & 2.20 & 2.20 & - & - & 3.13 & 3.13 \\
\hline FEM $_{\text {Elastic }}$ & 2.22 & 2.22 & 2.37 & 2.37 & $3.16,3.15$ * & $3.16,3.15$ * \\
\hline FEM $_{\text {ElasticPlastic }}$ & 1.53 & 1.50 & 1.55 & 1.49 & $1.90,1.88$ * & $1.81,1.80$ * \\
\hline FEM $_{\text {IsoKin }}$ & 1.71 & 1.60 & 1.71 & 1.61 & 2.20 & 2.00 \\
\hline $\mathrm{FEM}_{\text {Jacobs }}$ & 1.84 & 1.82 & 1.87 & 1.82 & $2.40,2.38^{*}$ & $2.32,2.31$ * \\
\hline $\mathrm{FEM}_{\text {Incefa }}$ & 1.83 & 1.84 & 1.85 & 1.84 & $2.35,2.34$ * & $2.35,2.34$ * \\
\hline Measured [13] & - & - & 1.51 & 1.46 & - & - \\
\hline
\end{tabular}

${ }^{*}$ CIEMAT finite element model results. ANSYS solver used, monotonic load applied up to $\varepsilon=1.2 \%$.

\subsection{SCK-CEN Specimen, the Effect of the Extensometer Position}

Within INCEFA-PLUS, SCK-CEN were the only ones measuring the gauge length in the environment during the experiment. An extensometer at the gauge section is used to control the displacements at the shoulder. However, since a crack can initiate at the points of contact between the extensometer and the sample in the PWR water environment, the extensometer is positioned slightly beyond the $10 \mathrm{~mm}$ gauge length, at the large $R=18 \mathrm{~mm}$ curvature section, where the cross section is larger and stresses due to the axial load are lower, decreasing the possibility of crack initiation at the contact points. The extensometer length, $L_{\text {ext }}$, which controls the displacement at the shoulder, is therefore higher, usually between 11 and $11.5 \mathrm{~mm}$. The effective/actual gauge length, $L_{\mathrm{g}}$, is therefore larger and equal to $L_{\mathrm{ext}}$. Such extensometer positioning is used to prevent crack initialization at the original (parallel) gauge length.

To study the impact of placing the extensometer above the gauge length, extensometer points in the finite element model are placed $0.5,0.75,1.00$ and $1.25 \mathrm{~mm}$ above the $10 \mathrm{~mm}$ gauge length (Figure 6), while the geometry and strain range $(\Delta \varepsilon=0.6 \%, 1.2 \%)$ are kept the same. Although the gauge length remains the same, the strain in the gauge section is calculated using the extensometer length, mimicking the experimental setup. Since the extensometer points are above the $10 \mathrm{~mm}$ gauge length, the S2G ratio decreases, as shown in Table 6. Lower strain ranges result in higher S2G ratios (the material is closer to the elastic state at which the $S 2 \mathrm{G}$ ratio is the highest), higher strain amplitude induces more plasticity and reduces the $\mathrm{S} 2 \mathrm{G}$ ratio. JACOBS constitutive model produces slightly higher S2G ratios compared to the INCEFA one. 


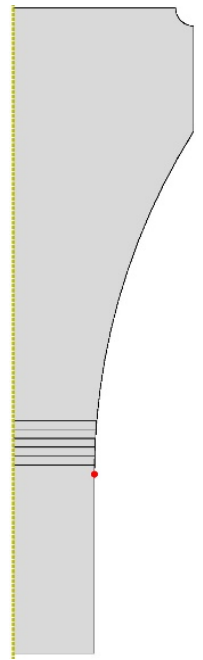

Original

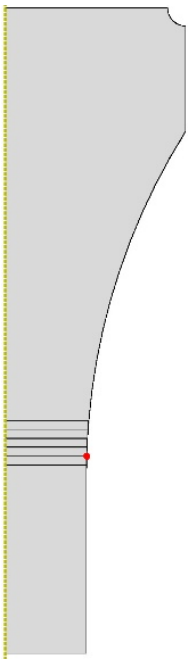

$+0.5 \mathrm{~mm}$

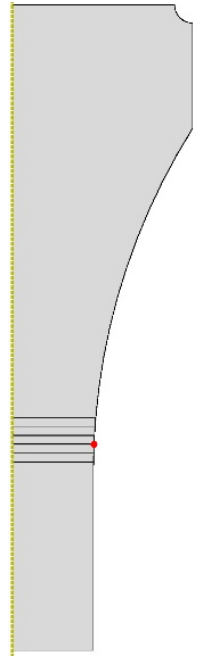

$+0.75 \mathrm{~mm}$

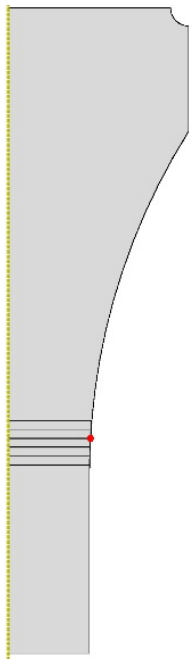

$+1.00 \mathrm{~mm}$

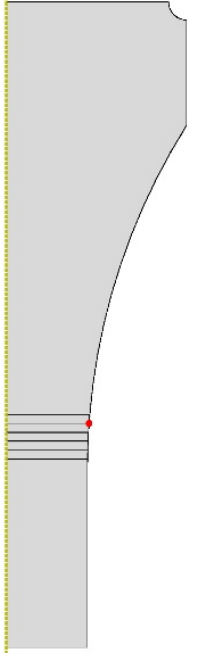

$+1.25 \mathrm{~mm}$

Figure 6. SCK-CEN specimen. Extensometer point positions (red dots).

Table 6. S2G values for SCK-CEN specimen: extensometer position effect.

\begin{tabular}{|c|c|c|c|c|c|}
\hline \multirow{2}{*}{ Extensometer Position (mm) } & \multirow[t]{2}{*}{ Effective Gauge Length (mm) } & \multicolumn{2}{|c|}{ S2G FEM JACOBS } & \multicolumn{2}{|c|}{ S2G FEM INCEFA } \\
\hline & & $\Delta \varepsilon=0.6 \%$ & $\Delta \varepsilon=1.2 \%$ & $\Delta \varepsilon=0.6 \%$ & $\Delta \varepsilon=1.2 \%$ \\
\hline Original & 10 & 1.87 & 1.82 & 1.85 & 1.84 \\
\hline+0.5 & $11.0=10+2 \times 0.50$ & 1.71 & 1.66 & 1.68 & 1.68 \\
\hline+0.75 & $11.5=10+2 \times 0.75$ & 1.64 & 1.59 & 1.61 & 1.60 \\
\hline+1.00 & $12.0=10+2 \times 1.00$ & 1.57 & 1.52 & 1.55 & 1.54 \\
\hline+1.25 & $12.5=10+2 \times 1.25$ & 1.51 & 1.47 & 1.49 & 1.48 \\
\hline Measured [13] & $10+X$ & 1.51 & 1.46 & 1.51 & 1.46 \\
\hline
\end{tabular}

For studying the effect of surface roughness on fatigue life, some specimens have been manufactured with a controlled rough surface finish by means of a grinding process. This grinding reduced the specimen diameter so that ground specimens have gauge sections diameters below the nominal values of $4.5 \mathrm{~mm}$, as shown in Table 7 . All the specimen have the same gauge length $(10 \mathrm{~mm})$. Additional FEM models were built to exactly match the measured dimensions of these specimens, including the matching extensometer lengths and, of course, the strain amplitudes (Table 7).

Table 7. S2G values for SCK-CEN specimen: extensometer position effect. Top part: $\Delta \varepsilon=0.6 \%$. Bottom part: $\Delta \varepsilon=1.2 \%$.

\begin{tabular}{|c|c|c|c|c|c|c|c|}
\hline Specimen & Surface & $\begin{array}{c}L_{\text {ext }} \\
(\mathrm{mm})\end{array}$ & $\begin{array}{c}D_{\mathrm{g}} \\
(\mathrm{mm})\end{array}$ & $\begin{array}{c}\Delta \varepsilon_{\text {meas }} \\
(\%)\end{array}$ & Meas@N25/2 & $\begin{array}{c}\text { S2G } \\
\text { FEM }_{\text {Jacobs }}\end{array}$ & FEM $_{\text {Incefa }}$ \\
\hline SC-2 & Smooth & 11.11 & 4.474 & 0.616 & 1.395 & 1.684 & 1.662 \\
\hline SC-5 & Rough & 11.40 & 4.230 & 0.626 & 1.448 & 1.621 & 1.600 \\
\hline SC-15 & Smooth & 11.16 & 4.474 & 0.610 & 1.642 & 1.679 & 1.656 \\
\hline SC-18 & Rough & 11.07 & 4.129 & 0.606 & 1.652 & 1.663 & 1.639 \\
\hline SC-31 & Rough & 12.00 & 4.155 & 0.626 & 1.454 & 1.538 & 1.519 \\
\hline SC-24 & Smooth & 11.15 & 4.481 & 0.618 & 1.506 & 1.679 & 1.657 \\
\hline SC-25 & Smooth & 11.18 & 4.475 & 0.622 & 1.591 & 1.673 & 1.651 \\
\hline SC-26 & Smooth & 11.82 & 4.476 & 0.640 & 1.430 & 1.583 & 1.564 \\
\hline Average & - & - & - & 0.620 & 1.51 & 1.64 & 1.62 \\
\hline SC-17 & Rough & 11.16 & 4.028 & 1.224 & 1.373 & 1.597 & 1.612 \\
\hline SC-19 & Rough & 11.16 & 4.071 & 1.244 & 1.441 & 1.601 & 1.617 \\
\hline SC-16 & Smooth & 11.23 & 4.475 & 1.228 & 1.498 & 1.624 & 1.642 \\
\hline SC-23 & Smooth & 10.78 & 4.463 & 1.228 & 1.542 & 1.690 & 1.708 \\
\hline Average & - & - & - & 1.231 & 1.46 & 1.63 & 1.64 \\
\hline
\end{tabular}




\subsection{JRC Specimen, L3 Length Effect}

The JRC shoulder displacement holder device is constructed in such a way that it measures the shoulder displacement at $L 3$ equal to several $\mathrm{mm}$, see Figure 7 . The $L 3$ section should be deformed only elastically (due to its larger diameter), therefore the L3 length should linearly increase the S2G ratio. The FEM results confirm this (Figure 7, Tables 8 and 9).
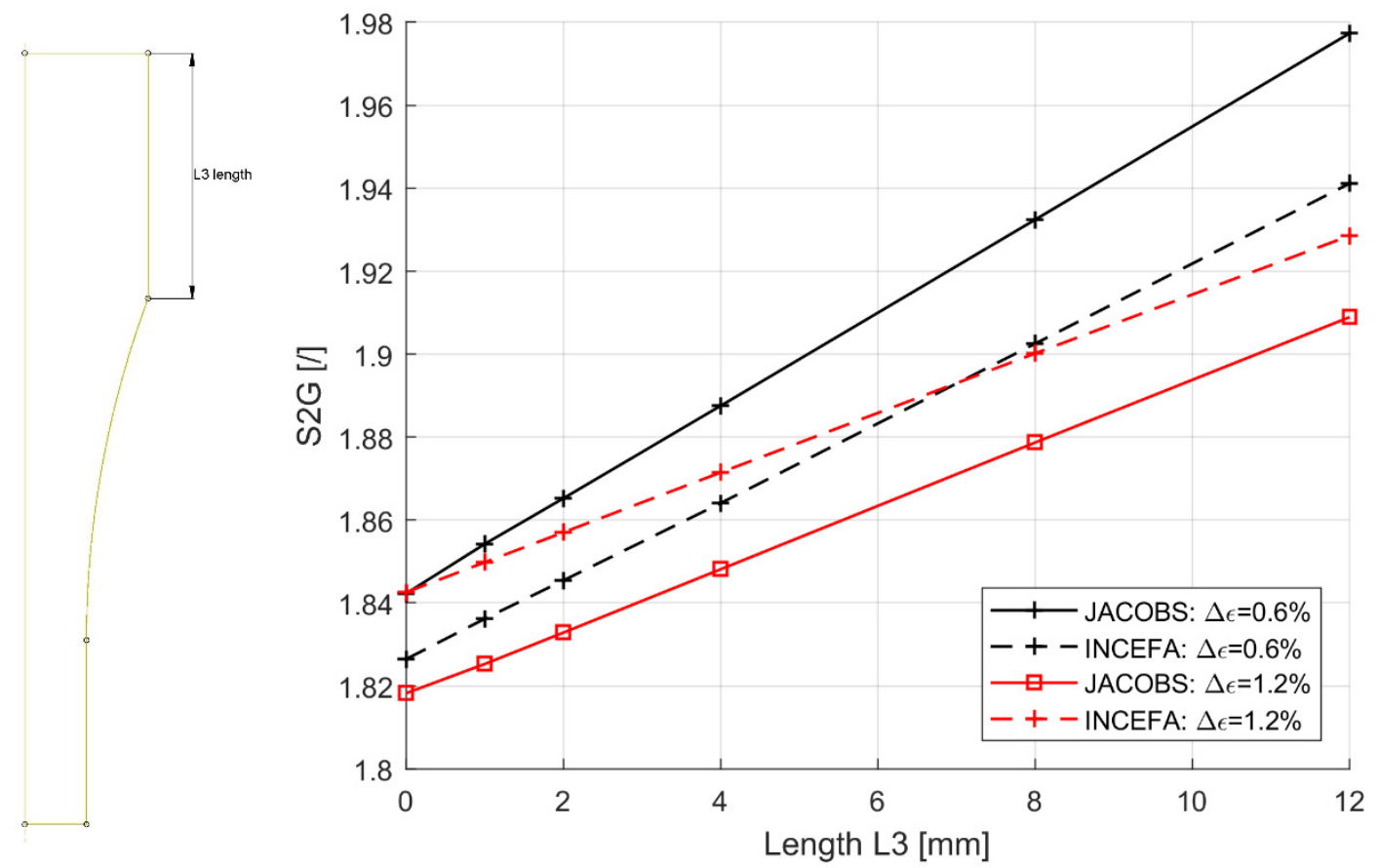

Figure 7. JRC specimen, the effect of $L 3$ length on the S2G ratio. Different responses at given $\Delta \varepsilon$ are due to different $K$ and $n$ material parameters (Table 3).

Table 8. JRC specimen ( $L 3$ length effect on $S 2 G$ values, FEM JACOBS).

\begin{tabular}{ccccccc}
\hline Case & $\mathbf{0}$ & $\mathbf{1}$ & $\mathbf{2}$ & $\mathbf{4}$ & $\mathbf{8}$ & $\mathbf{1 2}$ \\
\hline$\Delta \varepsilon=0.6 \%$ & 1.842 & 1.854 & 1.865 & 1.887 & 1.932 & 1.977 \\
$\Delta \varepsilon=1.2 \%$ & 1.818 & 1.825 & 1.833 & 1.848 & 1.879 & 1.909 \\
\hline
\end{tabular}

Table 9. JRC specimen (L3 length effect on S2G values, FEM INCEFA).

\begin{tabular}{ccccccc}
\hline \multirow{2}{*}{ Case } & \multicolumn{5}{c}{ L3 (mm) } \\
& $\mathbf{0}$ & $\mathbf{1}$ & $\mathbf{2}$ & $\mathbf{4}$ & $\mathbf{8}$ & $\mathbf{1 2}$ \\
\hline$\Delta \varepsilon=0.6 \%$ & 1.826 & 1.836 & 1.845 & 1.864 & 1.903 & 1.941 \\
$\Delta \varepsilon=1.2 \%$ & 1.842 & 1.850 & 1.857 & 1.871 & 1.900 & 1.928 \\
\hline
\end{tabular}

\section{Conclusions}

It is challenging to directly measure the gauge strain of a solid specimen in a PWR environment. The shoulder to gauge (S2G) ratio is often used for converting displacements at the shoulder to those at the gauge. In this work, finite element method is used to calculate this ratio for different specimen geometries. By knowing the S2G, the shoulder and corresponding cross head displacement for a required strain in the gauge section can be determined and set up for the experiment without the need for using the extensometer. Several constitutive laws are considered. The elastic calculation results in the highest S2G values and compares very well with the analytical values. However, this approach 
disregards the plastic deformation within the specimen, which mostly develops in the gauge section. The results with the constitutive law based on the JACOBS and INCEFA $\mathrm{N} 25 / 2$ fatigue curves are more representative and result in S2G values of 1.82-1.87 for both the JRC and the SCK-CEN specimen, for both $\Delta \varepsilon=0.6 \%$ and $\Delta \varepsilon=1.2 \%$. Since the CIEMAT specimen is significantly longer, its S2G values are between 2.32 and 2.40 at the same strain ranges. The FEM models are able to quantitatively capture the uncertainties of the S2G related to the uncertainties of the extensometer contact point at the shoulder (JRC specimen) or transition region (SCK-CEN specimen). The calculated S2G values for the SCK-CEN specimen are still somewhat higher compared to the available experimental results, in spite of accounting for the effective gauge length. In the previous work [13], S2G values were calculated with a nominal gauge length, which is lower than the effective one, and this resulted in lower S2G values. Calculating S2G ratio using elastic-plastic constitutive law based on the monotonic uniaxial tensile test should be avoided as they are significantly lower compared to the ones computed with elastic-plastic laws derived from hysteresis loops at half-life, N25/2.

Author Contributions: Conceptualization and original draft preparation: I.S. Formal analysis: I.S., A.M., K.M., P.G., N.P., M.B., J.L.W., G.B.M., S.A.G. Experimental measurements: M.V., R.N. Manuscript review: M.B., M.V. All authors have read and agreed to the published version of the manuscript.

Funding: The INCEFA-PLUS project has received funding from the Euratom Research and Training Programme 2014-2018 under Grant Agreement No. 662320.

Institutional Review Board Statement: Not applicable.

Informed Consent Statement: Not applicable.

Data Availability Statement: Requests to access the data presented in this study can be submitted to the data owner(s). The data are stored in a database and traceable through DOIs $[19,20]$ but are not publicly available due to the data policy of the project.

Conflicts of Interest: The authors declare no conflict of interest.

\section{References}

1. Chopra, O.; Stevens, G.L. Effect of LWR Coolant Environments on the Fatigue Life of Reactor Materials; Technical Report NUREG/CR6909; Rev. 1, U.S. Nuclear Regulatory Commission (NRC): Rockville, MD, USA, 2018.

2. Chopra, O.K.; Stevens, G.L.; Tregoning, R.; Rao, A.S. Effect of Light Water Reactor Water Environments on the Fatigue Life of Reactor Materials. J. Press. Vessel Technol. 2017, 139, 060801. [CrossRef]

3. Tice, D.R.; McLennan, A.; Gill, P. Environmentally Assisted Fatigue (EAF) Knowledge Gap Analysis: Update and Revision of the EAF Knowledge Gaps; Technical Report 3002013214; Electric Power Research Institute: Palo Alto, CA, USA, 2018.

4. Courtin, S.; Lefrançois, A.; le Duff, J.-A.; le Pécheur, A. Environmentally assisted fatigue assessment considering an alternative method to the ASME code case N-792. In Proceedings of the ASME 2012 Pressure Vessels \& Piping Conference, Toronto, ON, Canada, 15-19 July 2012.

5. Faidy, C. Status of French road map to improve environmental fatigue rules. In Proceedings of the ASME 2012 Pressure Vessels \& Piping Conference, Toronto, ON, Canada, 15-19 July 2012.

6. De Haan-de Wilde, F.H.E.; Hannink, M.H.C.; Blom, F.J. Overview of international implementation of environmental fatigue. In Proceedings of the ASME 2013 Pressure Vessels \& Piping Conference, Paris, France, 14-18 July 2013.

7. Métais, T.; Morley, A.; de Baglion, L.; Tice, D.; Stevens, G.L.; Cuvilliez, S. Explicit quantification of the interaction between PWR environment and component surface finish in environmental fatigue evaluation methods for austenitic stainless steels. In Proceedings of the American Society of Mechanical Engineers (ASME), Pressure Vessels and Piping Conference, Prague, Czech Republic, 15-20 July 2018; Volume 1A. PVP2018-84240.

8. Cuvilliez, S.; McLennan, A.; Mottershead, K.; Mann, J.; Bruchhausen, M. Incefa-Plus Project: Lessons Learned from the Project Data and Impact On Existing Fatigue Assessment Procedures. J. Press. Vessel Technol. 2020, 5, 061507S. [CrossRef]

9. Twite, M.; Platts, N.; McLennan, A.; Meldrum, J.; McMinn, A. Variations in measured fatigue life in LWR coolant environments due to different small specimen geometries. In Proceedings of the ASME 2016 Pressure Vessels \& Piping Conference, Vancouver, BC, Canada, 17-21 July 2016; Volume 1A.

10. Asada, S.; Tsutsumi, K.; Fukuta, Y.; Kanasaki, H. Applicability of hollow cylindrical specimens to environmental assisted fatigue tests. In Proceedings of the American Society of Mechanical Engineers (ASME), Pressure Vessels and Piping Conference, Waikoloa, HI, USA, 16-20 July 2017; Volume 1A. PVP2017-65514. 
11. Gill, P.; James, P.; Currie, C.; Madew, C.; Morley, A. An investigation into the lifetimes of solid and hollow fatigue endurance specimens using cyclic hardening material models in finite element analysis. In Proceedings of the American Society of Mechanical Engineers (ASME), Pressure Vessels and Piping Conference, Waikoloa, HI, USA, 16-20 July 2017; Volume A1. PVP2017-65975.

12. Mclennan, A.; Spätig, P.; le Roux, J.-C.; Waters, J.; Gill, J.B.P.; Platts, N. INCEFA PLUS project: The impact of using fatigue data generated from multiple specimen geometries on the outcome of a regression analysis. In Proceedings of the American Society of Mechanical Engineers (ASME), Pressure Vessels and Piping Conference, Virtual Conference, 3 August-1 November 2020. PVP2020-21422.

13. Vankeerberghen, M.; McLennan, A.; Simonovski, I.; Barrera, G.; Gomez, S.A.; Ernestova, M.; Platts, N.; Scibetta, M.; Twite, M. Strain control correction for fatigue testing in LWR environments. In Proceedings of the American Society of Mechanical Engineers (ASME), Pressure Vessels and Piping Conference, Virtual Conference, 3 August-1 November 2020. PVP2020-21373.

14. Procopio, I.; Cicero, S.; Mottershead, K.; Bruchhausen, M.; Cuvilliez, S. INCEFA-PLUS (Increasing safety in NPPs by covering gaps in environmental fatigue assessment). Procedia Struct. Integr. 2018, 13, 97-103. [CrossRef]

15. ASTM E606/E606M-19. Standard Test Method for Strain-Controlled Fatigue Testing; ASTM: West Conshohocken, PA, USA, 2019.

16. ISO 12106. Metallic Materials-Fatigue Testing-Axial-Strain-Controlled Method, 2nd ed.; IOS: 2017-03; ISO: Geneva, Switzerland, 2017.

17. Vankeerberghen, M.; Marmy, P.; Bens, L. PWR Fatigue Testing at SCK•CEN in the Framework of INCEFA+. In Proceedings of the 7th International Conference on Fracture Fatigue and Wear, Ghent, Belgium, 9-10 July 2018; pp. 225-240.

18. Akamatsu, M.; Chevallier, E. Chemical and Mechanical Characterization of the Materials Purchased for the Study of the Fatigue Behaviour of Austenitic Stainless Steels, T2-00-04 project (DOMZOME), Report HT4210010201A, EDF, 2001, page 18.

19. Cicero, R. Low Cycle Fatigue-Strain Control Test Data for AISI 304L ar Material at $300{ }^{\circ} \mathrm{C}$ and Nominal Strain Range of $6 \%$ (Sixth Nominally Repeat Test), European Commission JRC, DataSet. 2020. [CrossRef]

20. Cicero, R. Low Cycle Fatigue-Strain Control Test Data for AISI 304L ar Material at $300{ }^{\circ}$ C, European Commission JRC, DataSet. 2019. [CrossRef]

21. Platts, N.; Coult, B.; Zhang, W.; Gill, P. Negative R Fatigue Crack Growth Rate Testing on Austenitic Stainless Steel in Air and Simulated Primary Water Environments. In Proceedings of the American Society of Mechanical Engineers (ASME), Pressure Vessels and Piping ConferenceDivision (Publication) PVP, Prague, Czech Republic, 15-20 July 2018. PVP2018-84252.

22. Simonovski, I. INCEFA+, Finite Element Support; JRC Technical Report; European Commission, Joint Research Centre: Petten, The Netherlands, 2020. 